\title{
Rigid-Plastic Models for the Seismic Design and Assessment of Steel Framed Structures
}

\author{
C. Málaga-Chuquitaype ${ }^{1}$, A. Y. Elghazouli ${ }^{1}$, R. Bento ${ }^{2}$ \\ ${ }^{1}$ Department of Civil and Environmental Engineering, Imperial College London, UK \\ ${ }^{2}$ Department of Civil Engineering and Architecture, ICST, IST, Technical University of Lisbon, Portugal
}

\begin{abstract}
This paper demonstrates the applicability of response history analysis based on rigidplastic models for the seismic assessment and design of steel buildings. The rigid-plastic force-deformation relationship as applied in steel moment-resisting frames is re-examined and new rigid-plastic models are developed for concentrically braced frames and dual structural systems consisting of moment-resisting frames coupled with braced systems. This paper demonstrates that such rigid-plastic models are able to predict global seismic demands with reasonable accuracy. It is also shown that, the direct relationship that exists between peak displacement and the plastic capacity of rigid-plastic oscillators can be used to define the level of seismic demand for a given performance target.
\end{abstract}

Keywords: Rigid-plastic analysis, moment-resisting frames, concentrically-braced frames, seismic design.

\section{Introduction}

Several methods, of different levels of accuracy, are available for the structural analysis of steel buildings subjected to earthquake actions. Among them, non-linear dynamic analysis (also referred to as time-history) is widely recognized as the most reliable technique due to its ability to reflect the time dependent nature of the seismic behaviour. Nevertheless, its application in practical assesment and design is hampered by the high level of expertise it requires as well as the significant time and costs associated with it.

Modern earthquake resistant design philosophies aim to achieve reliable structural performance whilst maintaining an economic design by ensuring energy dissipation capabilities under strong ground-motions. Such energy dissipation is usually attained through high levels of plastic deformation in certain specially-designed elements whilst elastic behaviour is ensured in other structural members. If elastic deformations become relatively insignificant (e.g. at large deformation levels), rigid-plastic models can be adopted to asses the structural response. The relative simplicity of rigid-plastic models, coupled with the rationality of the response history approach, 
can introduce a great deal of ease and versatility to the analysis. The main assumption adopted in a rigid-plastic model is the disregard for any elastic deformation. This in turn means that the stiffness alternates between infinite and zero levels which may complicate its implementation within conventional stiffness-based computer methods. Nevertheless, the avoidance of elastic stiffness considerations introduces a great deal of simplicity as illustrated in subsequent sections of this paper. In general, rigid-plastic models also assume that all sources of energy dissipation are due to the plastic behaviour and hence non-hysteretic damping is ignored.

Despite its common use in studying the post-elastic behaviour under static loads, rigid-plastic models have not been widely employed in dynamic problems mainly due to the lack of suitable computational procedures. Another perceived problem is related to the inability of the method to deal with resonance effects, although it should be noted that resonant response decays rapidly as soon as non-linear deformations start to occur. One of the first studies dealing with rigidplastic approximations in the earthquake engineering field was the work by Newmark [1] who devised a method to estimate earthquake induced displacements on slope stability problems where relative displacements start to accumulate whenever the earthquake induced acceleration exceeds certain resistance thresholds. In fact, this viscous-like idealisation has become an important field of research in soil mechanics [2] and in the analysis of viscous dampers subjected to earthquake loading [3]. A few years later, Augusti [4] proposed general formulae for the solution of the dynamic response of framed structures based on rigid-plastic oscillators subjected to simple pulse and periodic loading. Strain hardening and strength degradation effects were partially considered in his study. Paglietti and Porcu [5], by means of the same classic rigid-plastic model, calculated the maximum displacement response of several SDOF systems to seismic loading. Their study also introduced the idea of the so called rigid-plastic spectrum defined as the relationship between a structural response parameter (such as peak structural displacement) and the plastic capacity of the rigid-plastic model. More recently, and based on such relationship, Domingues-Costa et al. [6] proposed an earthquake resistant design procedure for reinforced-concrete moment-resisting frames, the so-called Rigid-Plastic Seismic Design (RPSD), modifying the classical rigid-plastic model to take into account pinching effects typical of reinforced-concrete structures. This study highlighted the relative merits of rigidplastic approaches, which led to renewed interest in exploiting its advantages, particularly in terms of simplified seismic design and assessment procedures.

The principal advantage of using rigid-plastic models is related to their efficency in terms of modelling effort and computational time. As illustrated in this paper, the computational procedures are relatively straightforward, in comparison with advanced response-history analysis and necesitate a much lower degree of specialized knowledge and input. Most importantly, the definition of an appropriate rigid-plastic model requires the specification of a single key parameter: the plastic capacity capacity represented in terms of the strength at yield. This enables 
simple relationships to be established between the strength provided and a given structural performance parameter, which can be used for design purposes.

The present study extends the advantages associated with rigid-plastic models to different typologies of steel buildings under earthquake loading. To this end, new hysteretic relationships (as well as its corresponding integration algorithms) are proposed. It is shown that such rigidplastic models are able to predict global demand response histories with reasonable accuracy. Finally, relationships between peak displacement and the plastic capacity of rigid-plastic oscillators are used to obtain the required structural strength for a given target scenario.

\section{Moment-resisting frames (MRF)}

\subsection{Rigid-plastic idealization for single-degree-of-freedom systems}

Figure 1a presents a classic rigid-plastic oscillator of mass $m$, height $h$ and plastic moment capacity at the columns $M_{0}$, subjected to a ground acceleration $a_{g}(t)$. For such a rigid-plastic oscillator, the yield capacity of the structural system defined by $F_{y p}=-F_{y n}$ can be related to the limit moment at the plastic hinges by:

$$
F_{y p}=\frac{4 M_{0}}{h}
$$

similar conventions can be introduced for other, more complicated, rigid-plastic structures.

Figure $1 \mathrm{~b}$ presents the rigid-plastic response of the above described MRF oscillator as a function of lateral force and displacement. In this figure, two main behavioural states are evident: (i) a rigid state where the yield strength of the member is not reached and hence no displacement takes place and, (ii) a plastic state where deformations occur and the strength demand is equal to the yield strength.

Expression of dynamic equilibrium by means of D'Alembert's principle over the rigid-plastic oscillator of Figure 1a yields the following expression for the relative acceleration $a_{r}(t)$ as a function of time $t$ :

$$
a_{r}(t)=\frac{F(t)}{m}-a_{g}(t)
$$

where $F(t)$ represents the internal forces opposing the motion. With the previous assumptions and definitions, it can be inmediately recognised that Equation 2 can be replaced by the following set of relationships, which are more practical for computer-based numerical integration: 


$$
\begin{array}{ll}
a_{r}(t)=\frac{F_{y p}}{m}-a_{g}(t) & \text { if } v_{r}(t)>0 \\
a_{r}(t)=\frac{F_{y n}}{m}-a_{g}(t) & \text { if } v_{r}(t)<0 \\
a_{r}(t)=0 & \text { if } F(t) \in] F_{y n}, F_{y p}[
\end{array}
$$

where $v_{r}(t)$ is the relative velocity of the mass $m$, and hence a change of state occurs whenever $v_{r}(t)$ changes from positive or negative to zero. For this purpose, the numerical integration scheme presented in Figure 2 was implemented in MATLAB[7] and used in the present study. In this figure $d_{r}(t)$ is the relative displacement of the mass $m, \tau$ is the specific time at which the oscillator changes its behaviour from rigid to plastic or vice versa, $\Delta t$ is the integration time-step and $F_{y}$ takes the value of $F_{y p}$ if $v_{r}(t)>0$ or $F_{y n}$ if $v_{r}(t)<0$. Finally, the value of acceleration is assumed constant over a $\Delta t$ period of time.

Figure 1c presents a comparison between the seismic response in terms of displacement history of a rigid-plastic oscillator and a number of elasto-plastic SDOF models with elastic periods varying from 0.6 to 1.4 seconds, to the JMA record from the 1995 Kobe earthquake. This record imposes a peak demand of 6 times the yield strength of the structure or, in other words, a ratio between peak ground acceleration (PGA) and ground acceleration at yield $a_{y}$ of 6 . It should be noted, as pointed out by Paglietti and Porcu [5] that the single most important parameter governing the accuracy of rigid-plastic prediction is the overall contribution of elastic deformation. In other words, as expected for a given structure, the greater the ductility demand the more accurate the rigid-plastic prediction would be, in comparison with a conventional elastic-plastic model that does not account for strength degradation. In this case, the ductility demand is defined as the ratio between the peak displacement and the displacement at yield. This emphasises the suitability of the ratio between the PGA and the acceleration at structural yield for characterizing the accuracy of the rigid-plastic prediction approach. In turn, for the same ductility demand, the rigid-plastic model would give better estimates of peak displacement for stiffer structures.

\subsection{Response prediction of multi-degree-of-freedom systems}

In this section, the rigid-plastic model is applied to multi-storey moment-resisting frames by considering rigid-plastic behaviour at plastic hinges and rigid behaviour elsewhere. It is assumed that the displacement vector $s(x, t)$ at any location $x$ in the structure and at time $t$ can be represented by:

$$
s(x, t)=\delta(t) \Phi(x)
$$


where $\delta(t)$ represents the variation of the displacement at the effective height of the structure as a function of time and $\Phi(x)$ is the vector representing the shape of the plastic mechanism.

The response of a three-storey building designed by Bruneau et al. [8] and presented in Figure 3a is considered. Concentrated dead and superimposed loads of $250 \mathrm{kN}$ and $100 \mathrm{kN}$, respectively, are applied to the columns at each floor level and distributed loads of $15 \mathrm{kN} / \mathrm{m}$ and $10 \mathrm{kN} / \mathrm{m}$, corresponding to dead and live loads respectively, are applied to the beams along their length. The building was designed for drift-controlled behaviour and reduced beams section connections (RBS) were utilised.

Several non-linear elasto-plastic analyses were performed using the non-linear finite element program Adaptic [9] with due consideration of both material and geometric non-linearities. Cubic elasto-plastic 2D fiber elements were used for the beams and columns including the section variation at the RBS. An equivalent SDOF model was also defined as depicted in Figure 3a, with rigid-plastic behaviour in terms of lateral force and displacement at the effective height. As an example, the drift histories at the effective height of the building are compared in Figures $3 \mathrm{~b}$ and $3 \mathrm{c}$ when both models were subjected to the a scaled El Centro record and the JMA Kobe record.

Reasonably good agreement is observed in Figure 3 between the detailed elasto-plastic nonlinear model and the much simpler rigid-plastic oscillator. Although there are inevitable differences in the shape of the response, including the residual drift, the peak drift is farily well predicted. This favourable comparison is observed despite the limited inelastic demand imposed with ratios of PGA to acceleration at yield of 3 for El Centro and 2.21 for the JMA Kobe record. The correlation is expected to improve with the increase in inelastic demand.

\section{Concentrically-braced frames $(\mathrm{CBF})$}

The seismic performance of concentrically-braced frames (CBF) depends largely on the inelastic response of their bracing members. Indeed, design approaches in seismic codes typically aim to concentrate inelastic deformation in the bracing members while ensuring elastic behaviour in other parts of the structure by means of the application of capacity design principles and failure mode control [10].

The main behavioural aspects of the cyclic response of braces are: (i) successive elongation that causes yielding in tension to occur at increasing axial deformations and, (ii) gradual degradation of the compression resistance with increasing cycles. Several models have been proposed to estimate the cyclic response of bracing members $[11,12,13,14]$. Nevertheless such models 
require detailed input (e.g. nonlinear constitutive model for the material, discretization of the cross-section, member imperfections). In this section a simple modelling alternative is proposed through a rigid-plastic representation at the storey level. The model is validated against detailed elasto-plastic single and multi-storey representations, and its accuracy in predicting global peak displacement is examined.

\subsection{Rigid-plastic idealization for CBF}

The proposed rigid-plastic relationship for CBF is based initally on the behaviour of a singlestorey braced oscillator with pinned joints and rigid elements as shown in Figure 4a, where all the inelastic behaviour is concentrated in the bracing members.

Figure 4b presents the corresponding rigid-plastic hysteretic response in terms of storey drift and force. It is important to note that the model takes into account the tension elongation by allowing rigid behaviour only if the previous peak deformation is reached. Furthermore, the model assumes that the system is not able to sustain any load reversal until the load carrying capacity is recovered by tension action in the alternate brace, hence introducing effectively a slip-like behaviour. The adopted idealisation ignores the contribution of the braces in compression which in principle is acceptable for slender braces noting that the brace will buckle at a relatively early stage in the response history $[11,15]$. Where necessary, for bracing members with relatively low slenderness, an alternative model proposed in the next section can be used in order to take into account the contribution of the compression resistance of the bracing members.

Following the previous discussion, a new set of equations defining the rigid-plastic model can be devised:

$$
\begin{array}{lll}
a_{r}(t)=\frac{F_{y p}}{m}-a_{g}(t) & \text { if } & v_{r}(t)>0 \wedge d_{r}(t)>d\left(t_{p}\right) \\
a_{r}(t)=\frac{F_{y n}}{m}-a_{g}(t) & \text { if } & v_{r}(t)<0 \wedge d_{r}(t)<d\left(t_{n}\right) \\
a_{r}(t)=-a_{g}(t) & \text { if } & \left.F(t)=0 \wedge d_{r}(t) \in\right] d\left(t_{n}\right), d\left(t_{p}\right)[ \\
a_{r}(t)=0 & \text { if } & \left.v_{r}(t)=0 \wedge F(t) \in\right] F_{y n}, F_{y p}[
\end{array}
$$

where $t_{n}$ and $t_{p}$ are the instants of time at which the peak negative or positive displacement is reached, respectively, within a specific interval of time $[0, t]$. As a result, the integration algorithm proposed in Figure 5 can be used, where all variables are the same as defined before. Also, as in the previous section, the value of acceleration is considered constant over a $\Delta t$ period of time. 


\subsection{Response prediction of braced SDOF systems}

The response of the rigid-plastic oscillator presented in the previous section is validated herein against refined analyses where attention is placed on the prediction of the displacement history. The single-storey two-bay single-degree-of-freedom (SDOF) braced frame shown in Figure 4a is considered with 5 metres overall width and 2.9 metres height. A refined numerical model was constructed in Adaptic using pinned connections and rigid elements for all the structural members except the braces. The elastic modulus of steel is assumed as $200 \times 10^{3} \mathrm{~N} / \mathrm{mm}^{2}$ and its yield stress as $300 \mathrm{~N} / \mathrm{mm}^{2}$ with $0.5 \%$ of strain hardening. The braces were modelled with pinned ends and are formed of eight cubic elasto-plastic elements with 50 cross-sectional fibres. Several rectangular hollow sections were used which in turn signify a range of different member slenderness values. Notional loads at the midspan were used in order to simulate initial imperfections of the order of $1 / 200$ of the brace length.

The only parameter defining the rigid-plastic response is the storey shear capacity at yielding of the bracing system. This was calculated considering the plastic section capacity of the brace in tension only. Both models (i.e. detailed non-linear and rigid-plastic) were subjected to a range ground-motion acceleration histories. As an example, the rigid-plastic prediction is compared with the refined fibre-element model in Figures 4c and 4d for the case of a 50x2.5 SHS brace (member normalised slenderness $\bar{\lambda}$ of 1.00) to the El Centro record and for two different levels of magnification, namely $P G A / a_{y}$ about 3 and 4 . As shown in the figures, very good comparison is observed. The same favourable correlation was confirmed through further analyses with other ground-motion records.

Figure 6 explores the variation of the ratio between the peak drift predictions obtained by means of the rigid-plastic and the refined model as a function of slenderness and $P G A / a_{y}$ for the Beverly Hills Station record of the 1994 Northridge earthquake. As expected, the greater the ductility demand, the more accurate is the rigid-plastic approximation for a given value of slenderness. On the other hand, for stockier braces, the rigid-plastic model tends to overestimate the peak drift due to its lower energy dissipation capacity (narrower hysteresis loops) that ignores the contribution of compression resistance.

In general, good estimates of drift history can be expected for ratios of $P G A / a_{y}$ greater than three and slenderness larger than 1.5. Under these conditions the displacement error is typically less than $10 \%$. 


\subsection{Response prediction of multi-storey CBF systems}

In this section, the possibility of using the above-described rigid-plastic representation in estimating the seismic response of low-rise CBF is explored. The four-storey simple-braced structure presented in Figure 7, is considered herein. Figure 7 also presents the direction of analysis. All columns are assumed to be pinned at the base and simple beam connections are considered.

The building was designed to EC8 [16] employing seismic actions corresponding to Soil C conditions and Spectrum Type 1 together with a $P G A$ of $0.3 g$ and a behaviour factor of 4 . The dead load included the weight of partitions $\left(1 \mathrm{kN} / \mathrm{m}^{2}\right)$, finishing $\left(0.3 k \mathrm{~N} / \mathrm{m}^{2}\right)$ and a composite flooring system $\left(2.88 \mathrm{kN} / \mathrm{m}^{2}\right.$ on average), while $2.5 \mathrm{kN} / \mathrm{m}^{2}$ was considered as superimposed load.

As suggested in the code, the design assumed that all the lateral resistance is provided by the tension braces. Code limits related to second-order stability checks and inter-storey drift limits were satisfied in the design. Figure 8a presents the relationships between base shear and roof drift for the four-storey building obtained from a non-linear static analysis with a vertical distribution of loads following the fundamental modal shape. In the figure, the design base shear value is also represented and hence the overstrength due to the contribution of braces in compression is evident. It should be noted that the equivalent SDOF model employed in this study is based on the assumption that the response of the structure is dominated by the first mode of vibration, and that the design is based on achieving a plastic mechanism that avoids storey localisation.

The building was modelled in Adaptic with due account of material and geometric nonlinearities. Columns and braces were discretized in a number of finite elements with cubic shape functions. Initial imperfections at midlength of the braces were induced by means of the notional load method as described previously. The elastic modulus of steel was taken as $200 \times 10^{3} \mathrm{~N} / \mathrm{mm}^{2}$ and its yield stress as $300 \mathrm{~N} / \mathrm{mm}^{2}$ with $0.5 \%$ of strain hardening. This value of material strain hardening was assumed based on typical modelling practice. It is worth noting however that use of a value between $0 \%$ and $0.5 \%$ has no notable influence in the response within the level of displacement demand considered.

The equivalent rigid-plastic oscillator was defined in terms of the effective mass and height considering an inverted triangular distribution of displacements and a plastic resistance calculated from the nominal brace resistance in tension only. Both models were subjected to the El Centro and JMA Kobe records scaled so as to induce a peak force (computed from the PGA and the effective mass) of 3 times the base shear capacity of the building, respectively. The results in terms of drift at the effective height are presented in Figures $8 \mathrm{c}$ and $8 \mathrm{~d}$. 
It is evident form Figures $8 \mathrm{c}$ and $8 \mathrm{~d}$ that very good estimates of peak drift and close match in the drift response history are achieved over the strong part of the record. Nonetheless, after the strong demands cease to act, (particularly after 6 seconds in the response shown in Figure 8d) the actual structure responds more in an elastic fashion while the rigid-plastic model slips between the two rigid borders determined by the previous brace tension elongation limits (e.g. $d\left(t_{n}\right)$ and $d\left(t_{p}\right)$ in Equation 5). Such difference in response at the later stages of the drift history is caused by the absence of resistance in the rigid-plastic model during the slipping state whereas the actual building is able to dissipate some energy through compression resistance of the braces as indicated in Figure 8b. This in turn means that rigid-plastic approaches may perform better under pulse-like demands typical of near-field ground-motions. A procedure to overcome such limitations is proposed in the next section where a representation of compression resistance is introduced in the rigid-plastic model.

\section{Dual frames}

The asymmetric behaviour, member elongation and loss of compressive resistance associated with brace behaviour require considerable attention in design to avoid undesirable response mechanisms. In this respect, dual systems that combine moment resisting frames with concentric bracings, are often preferred in practice, owing to an enhanced seismic performance obtained by coupling the high ductility capacity of the moment frame with the improved lateral stiffness and capacity of the bracing system. Hence, an adequate rigid-plastic characterization of the seismic response of such dual frames is desirable.

\subsection{Rigid-plastic idealization of dual systems}

The single-storey oscillator presented in Figure 9a is used here in order to derive a simple rigid-plastic hysteretic approximation for dual structures. The seismic response of such oscillator combines the dissipative behaviour of bracing members at the storey level addressed in the previous section with flexural resistance in the columns where classic rigid-plastic hinges are formed. The related hysteretic behaviour in terms of force and storey drift is presented in Figure 9b.

Typically, the lateral resistance of the bracing system would exceed the lateral resistance of the moment frame. Consequently, the effects of the rigid-plastic hinges formed in the beams or columns will be to eliminate the slip behaviour periods where no resistance is present (i.e. as in the rigid-plastic model fro CBF shown in Figure 4b). This allows the structure to mobilize actions in reverse loading but with a net flexural resistance $F_{s n}$ or $F_{s p}$ provided by hinges in the MRF. In this idealisation, the possibility of internal classic rigid-plastic hysteresis loops is 
introduced whenever the system oscillates within the limits imposed by the elongated bracing members. The full lateral resistance is not recovered until the previous peak displacement is reached again. Hence, the set of equations defining the dual rigid-plastic response are derived as:

$$
\begin{gathered}
a_{r}(t)=\frac{F_{y p}}{m}-a_{g}(t) \quad \text { if } \quad v_{r}(t)>0 \wedge d_{r}(t)>d\left(t_{p}\right) \\
a_{r}(t)=\frac{F_{y n}}{m}-a_{g}(t) \quad \text { if } \quad v_{r}(t)<0 \wedge d_{r}(t)<d\left(t_{n}\right) \\
a_{r}(t)=\frac{F_{s p}}{m}-a_{g}(t) \quad \text { if } \quad F(t)=F_{s p} \wedge v_{r}(t)>0 \wedge d_{r}(t)<d\left(t_{p}\right) \\
a_{r}(t)=\frac{F_{s n}}{m}-a_{g}(t) \quad \text { if } \quad F(t)=F_{s n} \wedge v_{r}(t)<0 \wedge d_{r}(t)>d\left(t_{n}\right) \\
a_{r}(t)=0 \text { if } v_{r}(t)=0 \wedge\left(\begin{array}{c}
F(t) \in] F_{s n}, F_{s p}\left[\wedge d_{r}(t) \in\right] d\left(t_{n}\right), d\left(t_{p}\right)[ \\
\vee \\
F(t) \in] F_{y n}, F_{y p}\left[\wedge d_{r}(t) \in\left(d\left(t_{n}\right), d\left(t_{p}\right)\right)\right.
\end{array}\right)
\end{gathered}
$$

where $F_{s p}=-F_{s n}$ is the lateral resistance of the flexural plastic hinges formed in the MRF and $F_{y p}=-F_{y n}$ is the overall lateral strength of the system considering the strength contribution of the bracing system and other variables as previously defined.

\subsection{Response prediction of dual SDOF systems}

The proposed rigid-plastic model was validated against the results of detailed non-linear response history analyses for single-storey frames with fixed bases modelled in Adaptic. Cubic elasto-plastic elements with distributed plasticity were employed for the braces and columns. The elastic modulus of steel was taken as $200 \times 10^{3} \mathrm{~N} / \mathrm{mm}^{2}$ and the yield stress as $300 \mathrm{~N} / \mathrm{mm}^{2}$ with $0.5 \%$ strain hardening.

Rectangular Hollow Sections (RHS) were used for the braces and several cross-sections of braces and columns were employed in order to explore the variation of the accuracy of prediction with slenderness and two levels of flexural strength contribution. Figures $9 \mathrm{c}$ and $9 \mathrm{~d}$ present a typical comparison of drift histories. Figure 10 depicts the ratio of peak drift predictions obtained by means of the rigid-plastic and the refined non-linear model as a function of slenderness and $P G A / a_{y}$ subjected to the Beverly Hills Station record of the 1994 Northridge earthquake when $15 \%$ and $30 \%$ of the total lateral strength is contributed by flexural plastic hinges.

For records with very large PGA and more slender braces, the rigid-plastic approximation indicates a slight tendency to underestimate the peak drift predictions compared to the refined non-linear model. Nevertheless, in all cases the estimates are within the $\pm 10 \%$ band. In general, for the full range of slenderness studied here (from 1.3 to 2.1) the rigid-plastic procedure 
provided good predictions of peak displacements when the frame was subjected to acceleration time histories with PGA of 3 or more times the acceleration at yield.

\subsection{Response prediction of dual multi-storey frames}

In this section, the ability of the proposed rigid-plastic model is assessed against the prediction of displacement histories obtained by means of a detailed non-linear model of a four-storey building. The structure under consideration has the same plan configuration and elevation as the building presented in the previous section (Figure 7). However, in this case, fixed bases were assumed at the bottom of columns, hence a new design in accordance with EC8 [16] was performed. The same dead and superimposed loads used previously were utilized here. The pushover curve in terms of base shear and roof displacement of the modified building using a first-mode vertical distribution of loads is presented in Figure 11a. In this figure, the total design base shear value is also indicated.

The same modelling considerations described in Section 3.2 were adopted and both the detailed MDOF non-linear model and its equivalent rigid-plastic representation were used. The corresponding results in terms of drift at effective height are presented in Figures 11c and 11d, where good agreement over the whole response history can be observed. The El Centro record as well as the JMA Kobe earthquake record were scaled so as to induce a peak force (computed from the PGA and the effective mass) of 3 times the actual base shear capacity of the buildings.

Figure 11b presents the hysteretic response of the four-storey building when subjected to the El Centro record inducing a PGA of 3 times the yield acceleration of the equivalent rigid-plastic model. It is evident that the actual building develops greater lateral forces while oscillating between the rigid states, which is largely attributed to the contribution of compression forces in the braces that were not taken into account when calculating the oscillator's capacity. Nevertheless, this occurs over a relatively small period of time and hence favourable predictions are still achieved.

\section{$5 \quad$ Rigid-plastic design procedures}

\subsection{Relationship between strength and structural response}

As noted previously, the only parameter defining rigid-plastic models, such as the ones proposed in earlier sections, is the plastic capacity either in terms of yield force or moment. Even for dual systems, the contribution of the flexural plastic hinges to the overall lateral capacity of the structure can be expressed as a percentage of the total lateral strength. This makes response history analysis a relatively straightforward task once the lateral strength of the structure has 
been evaluated.

From another viewpoint, the single-parameter characteristic of rigid-plastic dynamics enables the evaluation of the required strength given a certain response target. In this context, plots of peak displacement as a function of the lateral capacity of the rigid-plastic oscillator have been proposed by Paglietti and Porcu [5] and refered to as rigid-plastic "spectra" to characterize the earthquake demand. This approach has been employed by Domingues-Costa et al. [17] to design reinforced concrete moment resisting frame structures. In this section, the principal characteristics which were already pointed out by previous researchers are summarized and the concept is further extended to steel structures, with particular emphasis on braced and dual frames.

Figure 12 presents a plot of the relationship between peak displacement and ultimate lateral capacity for a dual rigid-plastic oscillator such as the one presented in Figure 9. In this case the lateral resistance due to flexural action represents about $20 \%$ of the total lateral capacity of the structure. The curve was obtained by running a series of response history analyses for several values of lateral resistance and employing the Sylmar Station record of the 1994 Northridge $\mathrm{Mw}=6.5$ earthquake with $7.5 \mathrm{~km}$ source to site distance. The lateral resistance is expressed as a function of force divided by acceleration at the onset of plastic behaviour and the system mass, thus giving a non-dimensional value and facilitating the scaling of the curve for different values of yield capacity. It is worth noting that linear scaling of the mass or the acceleration time series will simply imply multiplying the ordinates of the curve by the corresponding scaling factor, which offers a great deal of versatility to plots of this form.

The point at which the curve crosses the horizontal axis corresponds to a lateral strength equal to the PGA times the mass of the oscillator. In turn, the point at which the curve crosses the vertical axis represents the peak ground displacement (PGD) since, at this point, no structural resistance is present and the equation of motion reduces to the double integration of the input acceleration.

Another feature of this type of relationship is the fact that the curve is not entirely smooth and some peaks and valleys do take place (for example at 0.1 of $F / m a_{y}$ in Figure 12 ). This reflects the dependence on the earthquake acceleration waveform signifying that different levels of strength may still give the same value of peak displacement (e.g. $0.5 \mathrm{~m}$ ).

\subsection{Rigid-plastic design of steel buildings}

In this section, the use of rigid-plastic relationships between yield capacity of the structure and response parameters for design purposes [17] is illustrated for dual steel frames. This is carried 
out through a design example of a six-storey braced building with fixed columns and constant storey height of $3.0 \mathrm{~m}$ which plan and elevation configurations are as presented in Figure 13.

The gravity loads and mass were calculated in the same way as described previously in Sections 3.3 and 4.3. The equivalent rigid-plastic oscillator was considered assuming a mechanism with yielding of the bracing members and formation of plastic hinges at the base of columns. Hence, the dual oscillator of Section 4 is used with an effective mass of $411505 \mathrm{~kg}$ and an effective height of 12.62 meters. An inverted triangular displacement shape was assumed and a target drift of $3.5 \%$ was used. Furthermore, a $20 \%$ contribution of the moment-resisting system at the base of the columns to the overall system resistance is considered as a design choice.

The seismic demand is represented by 8 records from the dataset developed for the SAC project [18] which are scaled in order to be consistent with a $2 \%$ probability of exceedance in 50 years for Los Angeles City, USA. The characteristics of these records are presented in Table 1. The first five records ( 1 to 5 ) were used to generate the rigid-plastic relationship between peak drift at effective height and base shear demand (presented in Figure 14), while the last three records (6 to 8 ) were used for validation purposes.

From Figure 14, a lateral resistance of at least $1000 \mathrm{kN}$ seems necessary to achieve the target drift of $3.5 \%$ (which corresponds to a displacement of $64 \mathrm{~cm}$ at the roof level). The average response of the whole set was used in recognition of the common engineering practice of focusing on average values. Other storey forces were calculated in accordance with the shape of the plastic mechanism assumed.

The design force for bracing members at the bottom storey was defined as $800 \mathrm{kN}$, while the force resisted by the flexural capacity of the plastic hinges assumed to form at the bottom of the columns was considered as $200 \mathrm{kN}$ (20\% as assumed previously). In fact, a UC203x 86 section at the bottom columns would have been enough to resist the gravity loads with due consideration of P- $\Delta$ effects if the whole lateral load was assigned to the braces. Nevertheless, a UC305x97 was used here to provide the $20 \%$ of flexural capacity assumed in the first step of the design process. The design of the braces was then performed but allowing for non-dimensional slenderness of up to 2.5 in order to achieve a close match between demand and capacity throughout the height of the building. Capacity design principles were followed for the seismic design of other members. The building was then subjected to the last three ground-motions of Table 1 , which are consistent with the same probability of exceedance of the target scenario, and the results are presented in Figure 15.

In general, good agreement is observed with an average peak drift of $3.7 \%$ compared to the target of $3.5 \%$ and a standard deviation in the peak roof drift of $\pm 0.3 \%$. In effect, the method- 
ology succeedd in combining the reliability of response history analysis techniques with the simplicity of rigid-plastic models with the aim of providing a reliable design based on structural performance at a given level. Indeed, it has been recognized that spectra in terms of the maximum plastic displacement are more convenient for design purposes than spectra in terms of maximum seismic acceleration and ductility factors [19, 20].

It is worth noting that previously proposed displacement-strength design relationships based on rigid-plastic response history used the so called "envelope" [6] with little or no correspondance with a specific earthquake scenario. In the present study the median value was considered as a more meaningful representation of such relationships. However, the median plus a number of standard deviations could also have been used but this would perhaps require a larger number of records in order to capture with confidence the variability associated with the process. Also, the displacement-plastic resistance curve expressed in terms of the median does not imply that such required strength will be associated with the median probability as the ability of the rigid-plastic oscillator varies as a function of the plastic resistance itself. Further studies are however required to provide additional validation, covering other structural configurations and earthquake records, for the methodology illustrated above.

In theory, a designer can follow an approach through which serviciability checks, associated with frequent events, can be carried out using conventional elastic models. On the other hand, validation of the structural response under extreme events can be performed using rigid-plastic approaches. This can be implemented in a performance-based design framework of the type presented in Figure 16. Such a design framework would allow reliability levels to be estimated with due account of the real earthquake variability. In addition, such framework would facilitate the understanding and selection of performace levels and enable different levels of structural optimization without the computational demand and inherent complexity associated with nonlinear finite element response-history analysis.

\section{Concluding remarks}

The applicability of rigid-plastic models in predicting the seismic behaviour of typical steel framed buildings has been investigated with particular emphasis on moment-resisting (MRF), concentrically-braced (CBF) and dual configurations. The principal advantage of using response history analysis based on rigid-plastic models has been highlighted as their ability to predict with good levels of accuracy, and for well-defined conditions, the structural response while keeping the computational costs and the detailed knowledge required at a relatively low level.

For MRF, the classical rigid-plastic model was used in conjunction with the transformation of 
a MDOF into an equivalent SDOF representation based on a specified plastic mechanism. It has been shown that such rigid-plastic model can give good estimates of global deformations when relatively high levels of non-linear response (typically for PGA/ $a_{y}>3$ ) are expected. On the other hand, for $\mathrm{CBF}$ and dual systems, this paper proposed new rigid-plastic hysteretic models that take into consideration the specific behavioural characteristics of such structural configurations. In addition, for the newly developed models, this study has shown that in general, good estimates can be achieved if the ground-motion pushes the structure well into the inelastic range with the ratio of PGA over acceleration at yield serving as a good parameter to quantify such ability.

It was shown in this paper that the more slender the braces in CBF systems, the better the response prediction obtained from the idealise rigid-plastic model suggested in Section 4, particularly when braces with a non-dimensional slenderness greater than 1.5 are employed. Nevertheless, when the contribution of flexural strength is taken into account, such dependance on the slenderness value is reduced and the response is adequately predicted for the whole range of slenderness studied herein (from 1.3 to 2.1). An additional parameter affecting the accuracy of rigid-plastic models for dual systems was shown to be the extent of flexural strength contribution to the total lateral capacity of the system. In general, when the flexural plastic hinge contribution increases, the rigid-plastic model tends to underestimate the displacement response, but such underestimation was tyically less than $10 \%$ for all the cases considered. Besides, the rigid-plastic idealizations employed in this study also share the limitations of equivalent SDOF representations, and require the selection of a pre-defined plastic mechanism. The approach is therefore suitable for regular low and medium-rise structures which are dominated by the first mode of vibration, and in which a pre-defined plastic mechanism is ensured. In addition, the rigid-plastic model does not account for strength degradation which may be present under severe cyclic conditions.

Finally, the potential use of design methodologies based on rigid-plastic relationships between plastic capacity and demand parameters was illustrated, although this needs to be examined further in future studies covering more buildings and a larger data set of records. Overall, the results presented in this paper suggest that rigid-plastic models can be used in some situations as a simple approach for predicting seismic response.

\section{References}

[1] Newmark N. Effects of earthquakes on dams and embankments, Fifth Rankine Lecture. Géotechnique 1965; 2:139-160.

[2] Enoki M, Xuan Luong B, Okabe N, Itou K. Dynamic theory of rigid-plasticity. Soil Dynamics and Earthquake Engineering 2005; 25:635-647. 
[3] Vafai A, Hamid M, Ahmadi G. Numerical modeling of MDOF structures with sliding supports using rigid-plastic link. Earthquake Engineering and Structural Dynamics 2001; 30:27-42.

[4] Augusti G. Rigid-plastic structures subject to dynamic loads. Meccanica 1969; 5:74-84.

[5] Paglietti A, Porcu MC. Rigid-plastic approximation to predict plastic motion under strong earthquakes. Earthquake Engineering and Structural Dynamics 2001; 30:115-126.

[6] Domingues-Costa J, Bento R, Levtchitch V, Nielsen M. Rigid-plastic seismic design of reinforced concrete structures. Earthquake Engineering and Structural Dynamics 2006; 36:55-76.

[7] MATLAB. 7.3 Getting Started Guide, The MathWorks Inc., USA 2006.

[8] Bruneau M, Uang C, Whittaker A. Ductile design of steel structures. McGraw-Hill, 1998.

[9] Izzuddin B. Nonlinear dynamic analysis of framed structures. PhD Thesis, Department of Civil and Environmental Engineering, Imperial College London, UK 1991.

[10] Elghazouli A. Seismic design procedures for concentrically braced frames. Proceedings of the Institution of Civil Engineers, Structures and Buildings 2003; 156:381-394.

[11] Broderick B, Elghazouli A, Goggins J. Earthquake testing and response of concentrically-braced sub-frames. Journal of Constructional Steel Research 2008; 64:997-1007.

[12] Ikeda K, Mahin S. A refined physical theory model for predicting the seismic behaviour of braced frames. Report UMEE 77r3. Technical Report, Department of Civil Engineering, University of Michigan, USA. 1984.

[13] Georgescu D, Toma C, Gosa O. Post-critical behaviour of K braced frames. Journal of Constructional Steel Research 1991; 21:115-133.

[14] Remennikov AM, Walpole W. Analytical prediction of seismic behaviour for concentrically braced steel systems. Earthquake Engineering and Structural Dynamics 1997; 26:859-874.

[15] Elghazouli A, Broderick B, Goggins J, Mouzakis H, Carydis P, Bouwkamp J, Plumier A. Shake table testing of tubular steel bracing members. Proceedings of the Institution of Civil Engineers, Structures and Buildings 2005; SB4:229-241.

[16] CEN. EN 1998-1, Eurocode 8: Design provisions for earthquake resistance of structures, part1: General rules, seismic actions and rules for buildings 2005.

[17] Domingues-Costa J, Bento R, Levtchitch V, Nielsen M. Simplified non-linear time-history analysis based on the theory of plasticity. Earthquake Resistant Engineering Structures V, 2005.

[18] SAC. Develope suites of time histories 1997.

[19] Fajfar P. Capacity spectrum method based on inelastic demand spectra. Earthquake Engineering and Structural Dynamics 1999; 28:979-993.

[20] Priestley M. Myths and fallacies in earthquake engineering, revisited. The ninth Mallet Milne Lecture. IUSS Press, Pavia, Italy, 2003. 


\section{Tables}

Table 1: Characteristics of Los Angeles ground-motions [18] with a 2\% probability of exceedance in 50 years, used for the design example.

\begin{tabular}{|c||c||c||c||c||c||c|}
\hline ID & $\begin{array}{c}\text { Earthquake } \\
\text { Name }\end{array}$ & $\begin{array}{c}\text { Magnitude } \\
M_{w}\end{array}$ & $\begin{array}{c}\text { Distance } \\
{[\mathrm{km}]}\end{array}$ & $\begin{array}{c}\text { Scale } \\
\text { Factor }\end{array}$ & $\begin{array}{c}\text { Duration } \\
{[\mathrm{s}]}\end{array}$ & $\begin{array}{c}\text { PGA } \\
{\left[\mathrm{m} / \mathrm{s}^{2}\right]}\end{array}$ \\
\hline 1 & 1995 Kobe & 6.9 & 3.4 & 1.15 & 59.98 & 9.03 \\
\hline 2 & 1989 Loma Prieta & 7 & 3.5 & 0.82 & 24.99 & 4.64 \\
\hline 3 & 1994 Northridge & 6.7 & 6.4 & 1.61 & 59.98 & 9.09 \\
\hline 4 & 1994 Northridge & 6.7 & 6.4 & 1.61 & 59.98 & 1.3 \\
\hline 5 & 1974 Tabas & 7.4 & 1.2 & 1.08 & 49.98 & 9.73 \\
\hline 6 & 1994 Northridge & 6.7 & 7.5 & 1.29 & 14.95 & 9.25 \\
\hline 7 & 1974 Tabas & 7.4 & 1.2 & 1.08 & 49.98 & 7.93 \\
\hline 8 & Elysian Park (simulated) & 7.1 & 17.5 & 1.43 & 29.99 & 1.27 \\
\hline
\end{tabular}




\section{Figures}
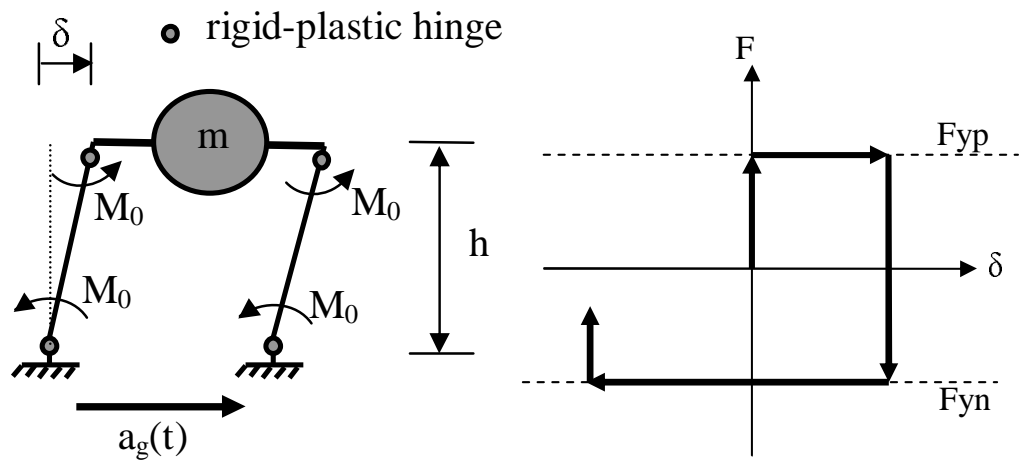

(a) MRF rigid-plastic oscillator.

(b) Force-displacement rigidplastic response.

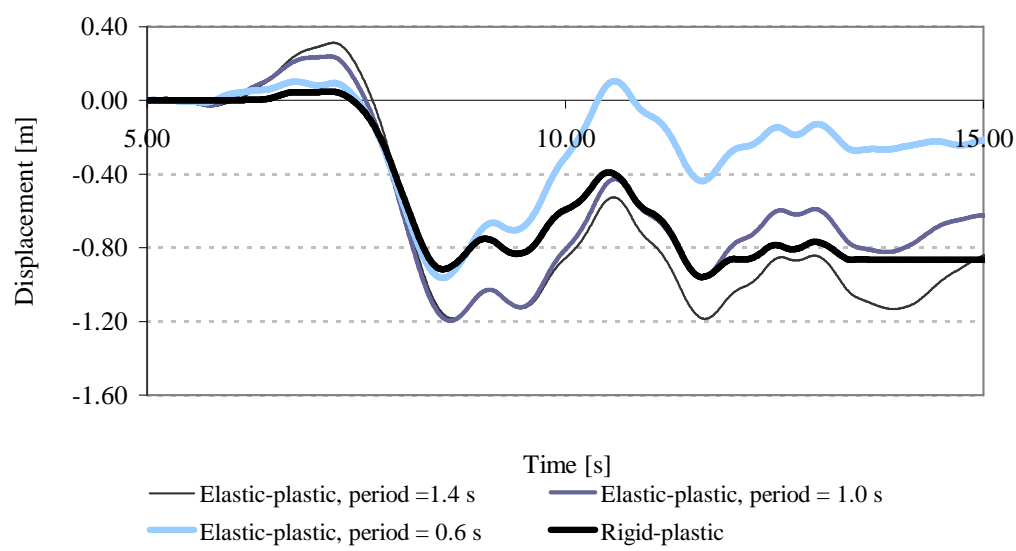

(c) Rigid-plastic and elastic-plastic displacement histories of SDOFs subjected to the scaled JMA record from the 1995 Kobe earthquake with $P G A / a_{y}=6$.

Figure 1: Rigid-plastic oscillator subjected to ground-motion excitation. 


$$
\begin{aligned}
& i\left(\begin{array}{l}
\text { Rigid behaviour } \\
F(t)=m a_{g}(t) \\
a_{r}(t)=0 \\
v_{r}(t)=0 \\
d_{r}(t)=d_{r}(t-\Delta t)
\end{array}\right. \\
& \Downarrow \\
& \text { if } F(\tau) \notin] F_{y n}, F_{y p}[\Longrightarrow t=t+\tau \Longrightarrow \text { go to } i i \\
& \text { else } \Longrightarrow t=t+\Delta t \Longrightarrow \quad \text { go to } i \\
& \Downarrow \\
& i i\left(\begin{array}{l}
\text { Plastic behaviour } \\
F(t)=F_{y} \\
a_{r}(t)=\frac{F(t)}{m}-a_{g}(t) \\
v_{r}(t)=a_{r}(t) \cdot \Delta t+v_{r}(t+\Delta t) \\
d_{r}(t)=a_{r}(t) \cdot \frac{\Delta t^{2}}{2}+v_{r}(t) \cdot \Delta t+d_{r}(t-\Delta t)
\end{array}\right. \\
& \text { if } v_{r}(\tau)=0 \Longrightarrow t=t+\tau \Longrightarrow \text { go to } i \\
& \text { else } \Longrightarrow t=t+\Delta t \Longrightarrow \quad \text { go to } i i
\end{aligned}
$$

Figure 2: Integration algorithm for rigid-plastic moment-resisting frames. 


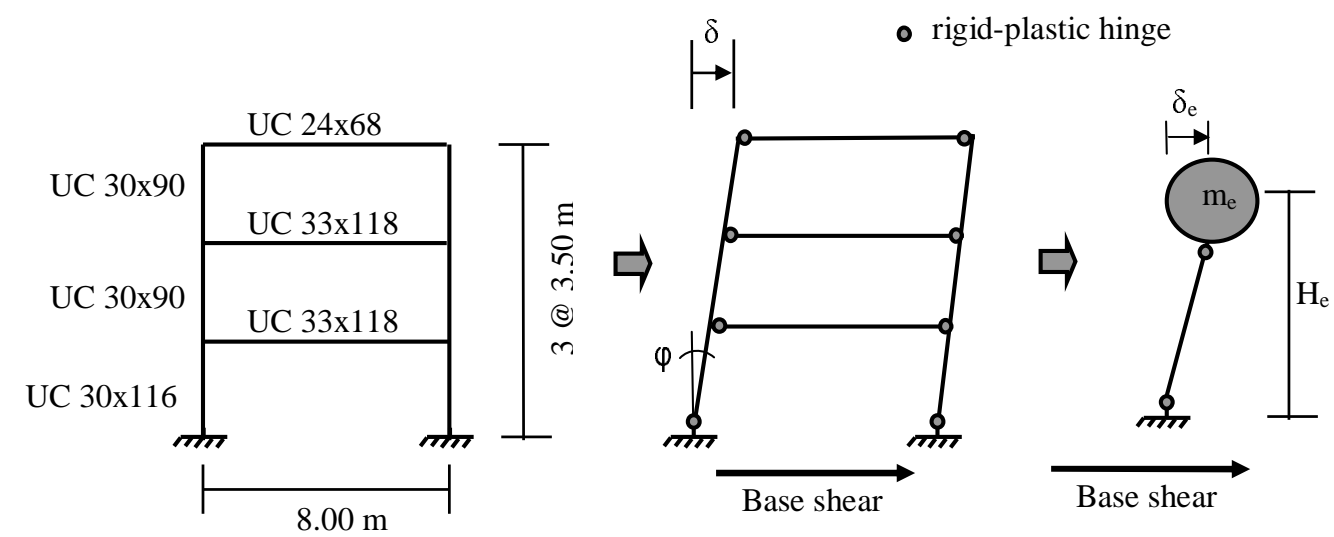

(a) Three-storey MRF designed by Bruneau et al. [8] (left), assumed rigid-plastic mechanism (centre) and equivalent rigid-plastic SDOF (right).

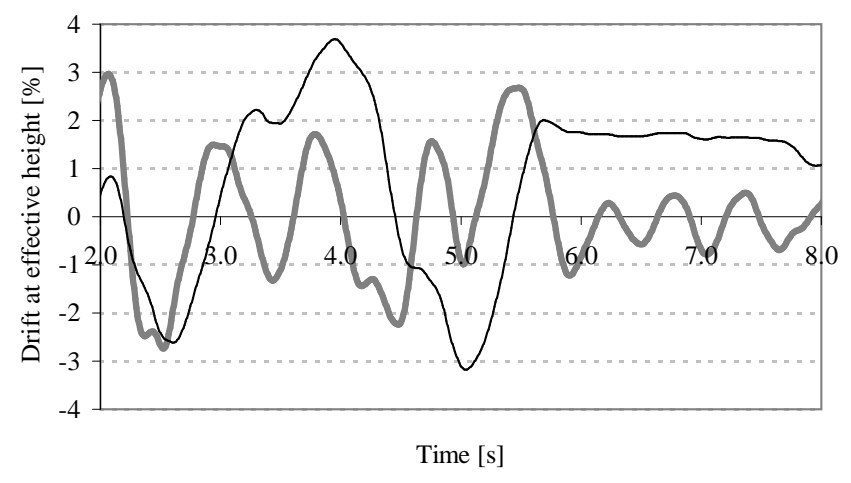

- Non-linear MDOF — Rigid-plastic equivalent SDOF

(b) Drift histories at effective height under El Centro record.

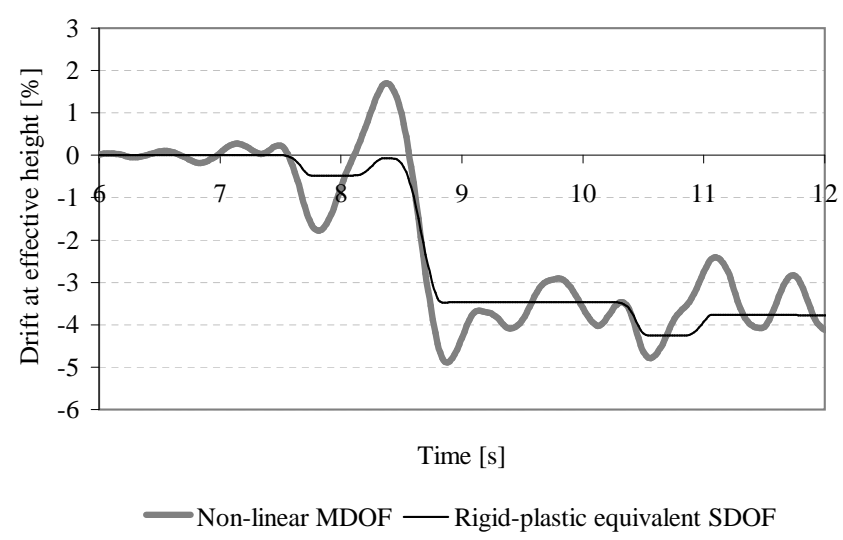

(c) Drift histories at effective height under the JMA Kobe earthquake record.

Figure 3: Rigid-plastic analysis of a MDOF MRF. 


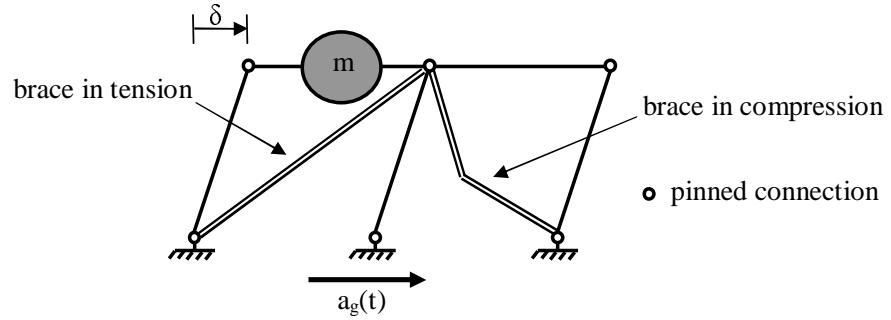

(a) Cocentrically-braced frame with pinned connections subjected to ground-motion.

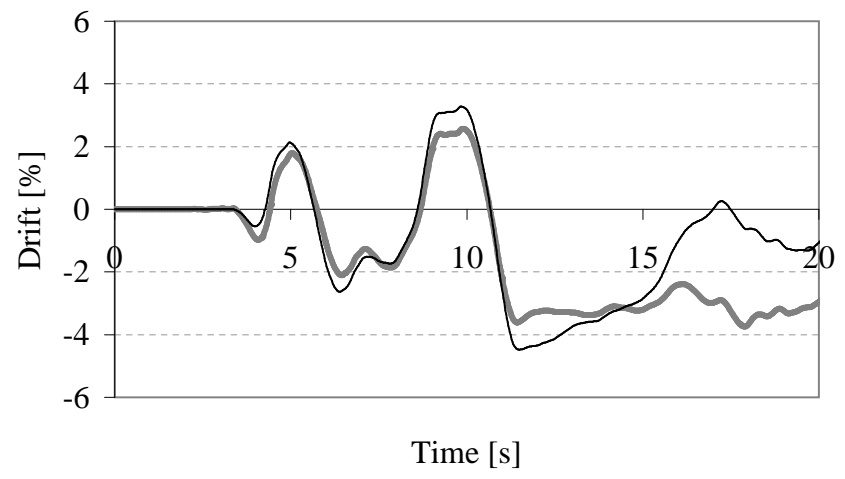

— Refined non-linear — Rigid-plastic

(c) Roof drift histories for $\bar{\lambda}=1.00$ under El Centro record with $P G A / a_{y}=3$.

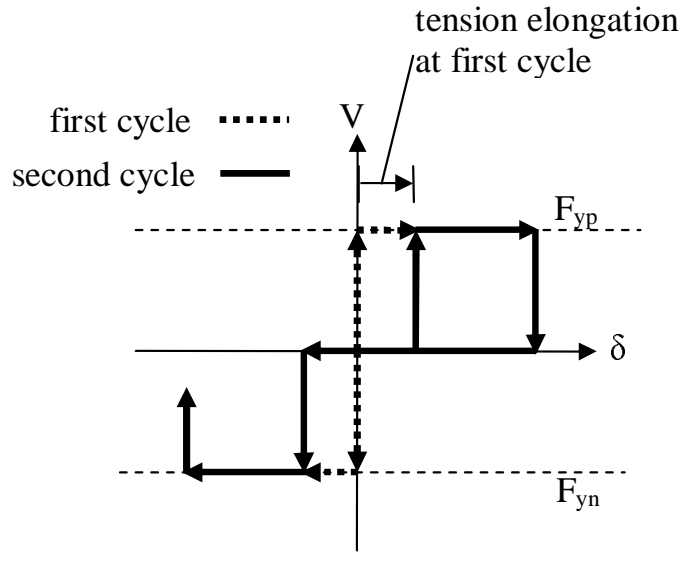

(b) Equivalent rigid-plastic response of $\mathrm{CBF}$ at storey level.

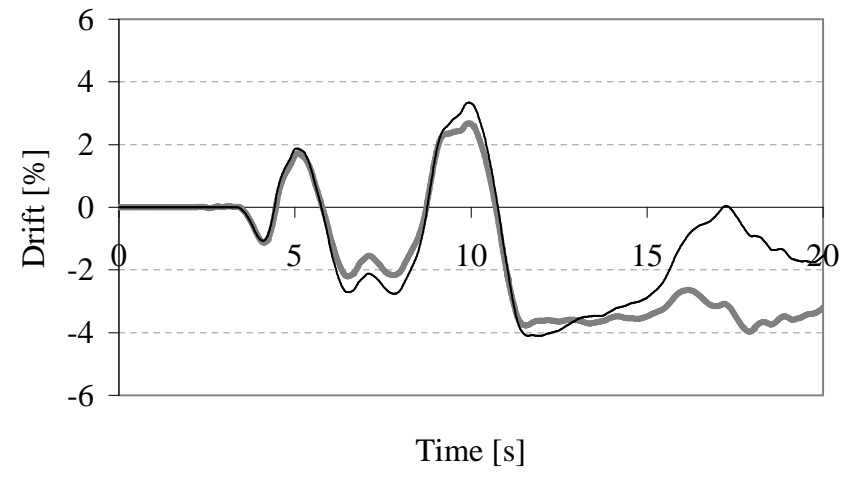

— Refined non-linear — Rigid-plastic

(d) Roof drift histories for $\bar{\lambda}=1.00$ under El Centro record with $P G A / a_{y}=4$.

Figure 4: Rigid-plastic analysis of a SDOF CBF. 


$$
\begin{aligned}
& i\left(\begin{array}{l}
\text { Rigid behaviour } \\
F(t)=m a_{g}(t) \\
a_{r}(t)=0 \\
v_{r}(t)=0 \\
d_{r}(t)=d_{r}(t-\Delta t)
\end{array}\right. \\
& \Downarrow \\
& \text { if } F(t) \in] F_{y n}, F_{y p}\left[\wedge F(t) \cdot d_{r}(t)>0 \Longrightarrow t=t+\Delta t \Longrightarrow \text { go to } i\right. \\
& \text { elseif } F(\tau) \cdot d_{r}(\tau)<0 \wedge d\left(t_{n}\right) \cdot d\left(t_{p}\right) \neq 0 \Longrightarrow t=t+\tau \Longrightarrow \text { go to } \text { iii } \\
& \text { elseif } F(\tau) \notin] F_{y n}, F_{y p}[\Longrightarrow t=t+\tau \Longrightarrow \text { go to } i i \\
& i i\left(\begin{array}{l}
\text { Plastic behaviour } \\
F(t)=F_{y} \\
a_{r}(t)=\frac{F(t)}{m}-a_{g}(t) \\
v_{r}(t)=a_{r}(t) \cdot \Delta t+v_{r}(t-\Delta t) \\
d_{r}(t)=a_{r}(t) \cdot \frac{\Delta t^{2}}{2}+v_{r}(t) \cdot \Delta t \\
+d_{r}(t-\Delta t)
\end{array}\right. \\
& \Downarrow \\
& \Downarrow \\
& i i i\left(\begin{array}{l}
\text { Slip behaviour } \\
F(t)=0 \\
a_{r}(t)=-a_{g}(t) \\
v_{r}(t)=a_{r}(t) \cdot \Delta t+v_{r}(t-\Delta t) \\
d_{r}(t)=a_{r}(t) \cdot \frac{\Delta t^{2}}{2}+v_{r}(t) \cdot \Delta t \\
+d_{r}(t-\Delta t)
\end{array}\right. \\
& \Downarrow
\end{aligned}
$$

Figure 5: Integration algorithm for rigid-plastic concentrically-braced frames. 


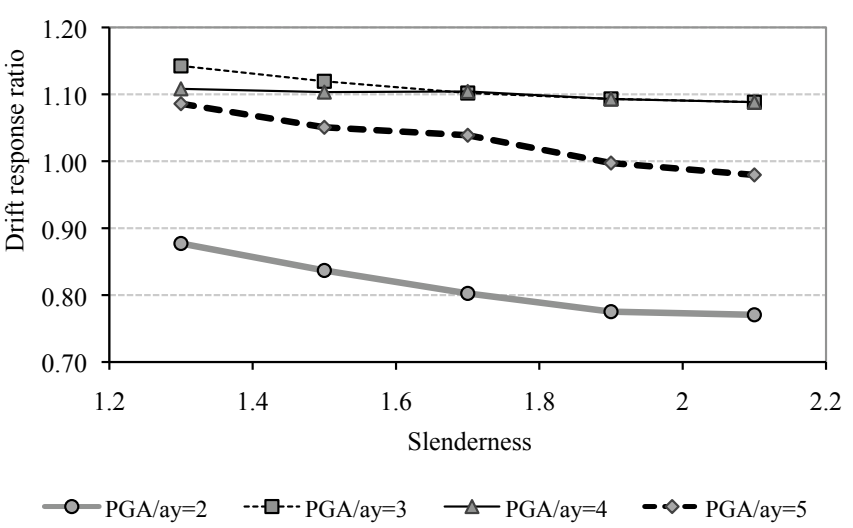

Figure 6: Ratio of peak drift predictions (rigid-plastic to non-linear model) as a function of slenderness and $P G A / a_{y}$ for the Beverly Hills Station 1994 Northridge Earthquake record. 

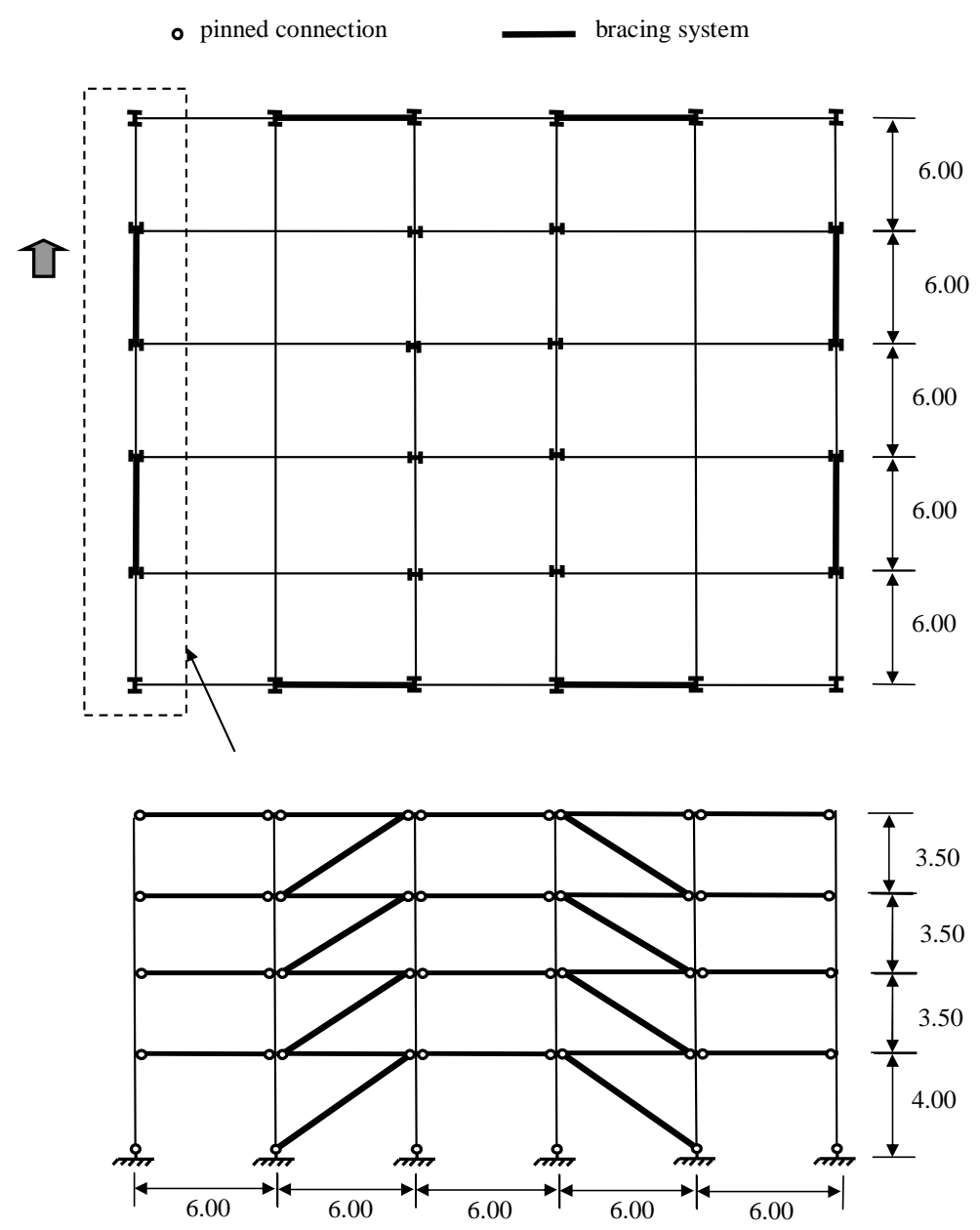

Figure 7: Plan layout and elevation of the four-storey CBF under study. 


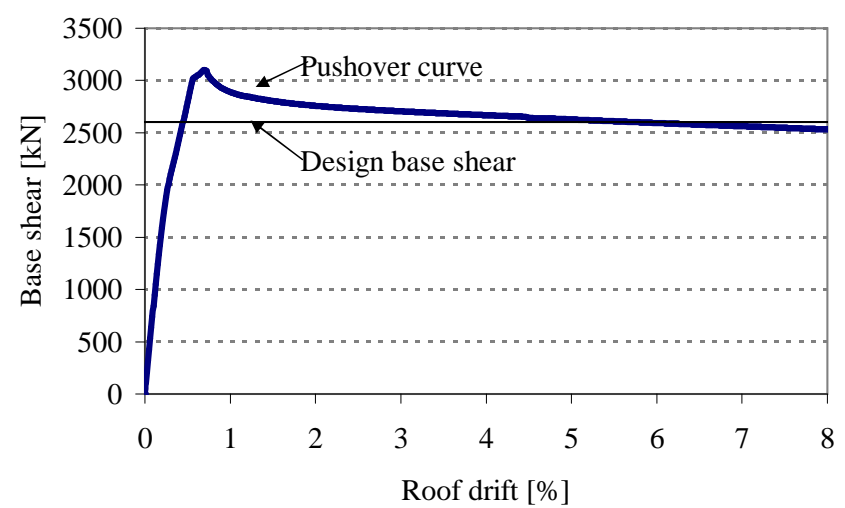

(a) Pushover curve for the four-storey CBF structure.

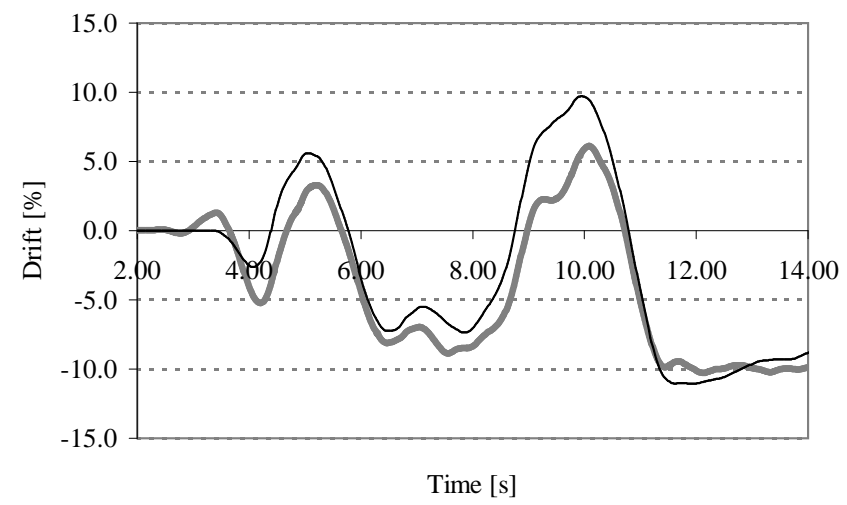

Refined non-linear —_Equivalent rigid-plastic

(c) Drift histories at effective height under scaled El Centro record with $P G A / a_{y}$ of 3 .

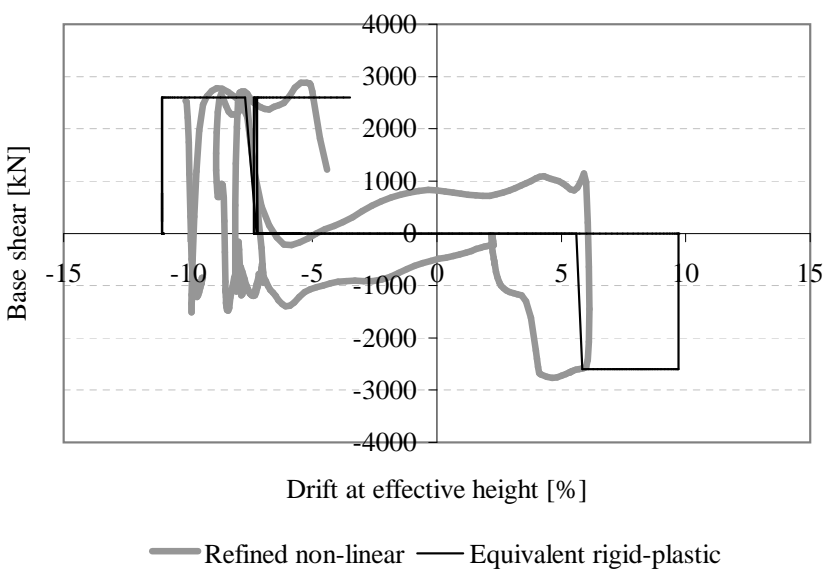

(b) Hysteretic behaviour of the four-storey building and the rigid-plastic model under scaled El Centro record with $P G A / a_{y}$ of 3 .

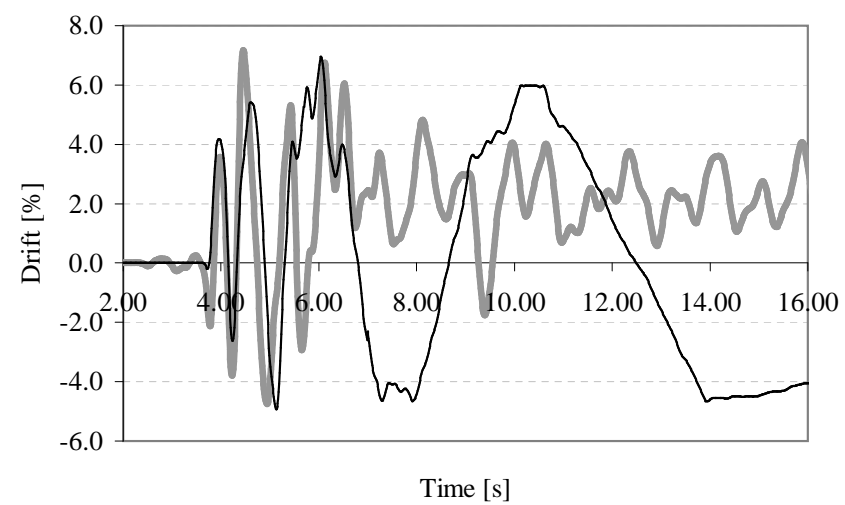

Refined non-linear ——Equivalent rigid-plastic

(d) Drift histories at effective height under scaled JMA Kobe record with $P G A / a_{y}$ of 3 .

Figure 8: Rigid-plastic analysis of a four-storey CBF. 


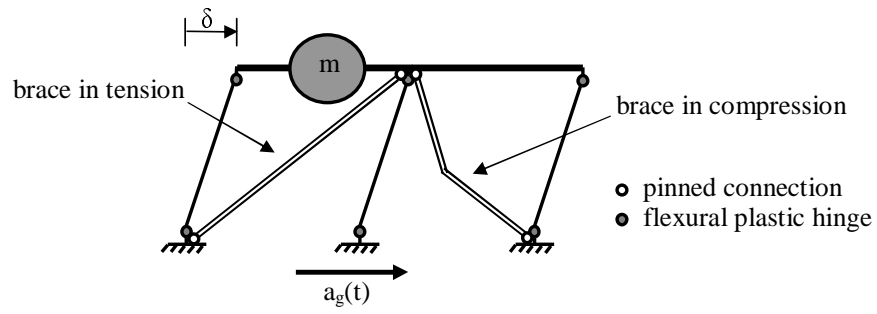

(a) Concentrically-braced frame with fixed connections subjected to ground-motion.

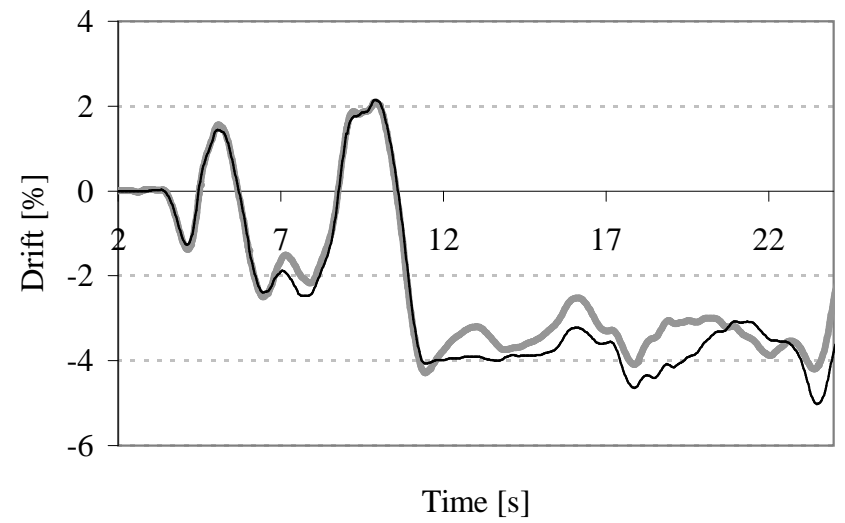

- Refined non-linear — Rigid-plastic

(c) Roof drift histories for $\bar{\lambda}=1.30$ and flexural plastic hinges contributing $17 \%$ of the total resistance under El Centro record with $P G A / a_{y}=4$.

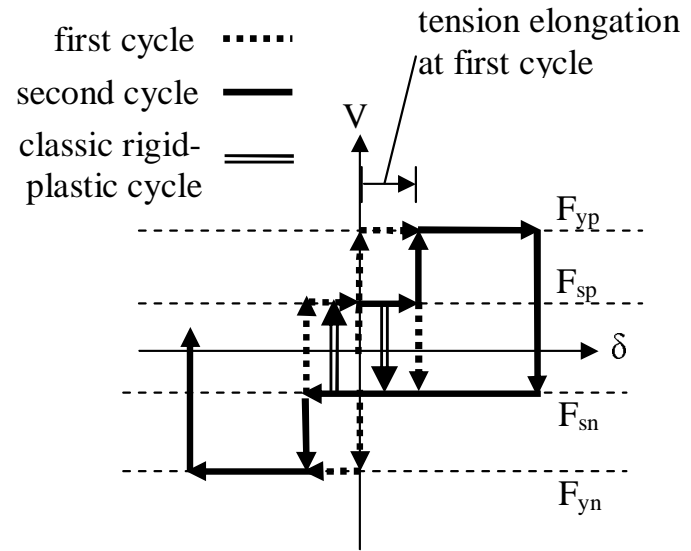

(b) Equivalent rigid-plastic response of dual structure at storey level.

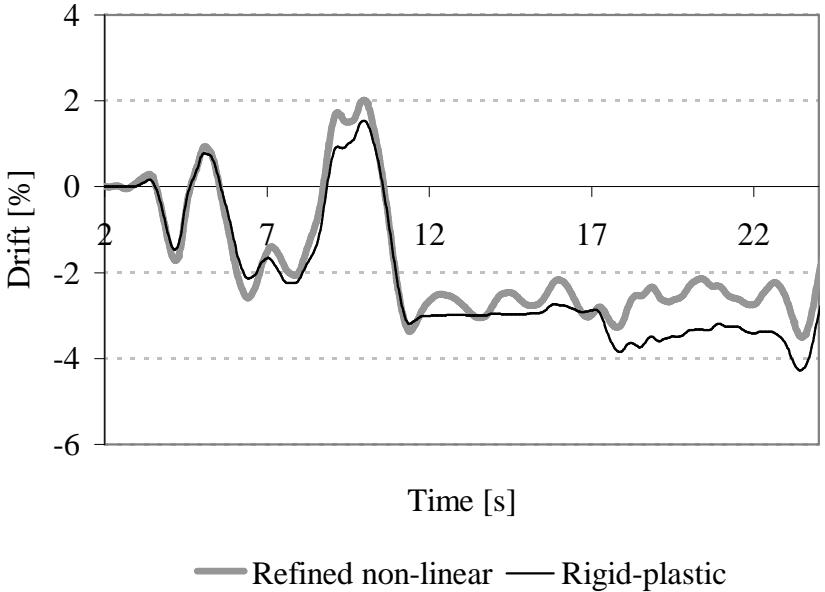

(d) Roof drift histories for $\bar{\lambda}=1.30$ and flexural plastic hinges contributing $32 \%$ of the total resistance under El Centro record with $P G A / a_{y}=4$.

Figure 9: Rigid-plastic analysis of dual SDOF structures. 


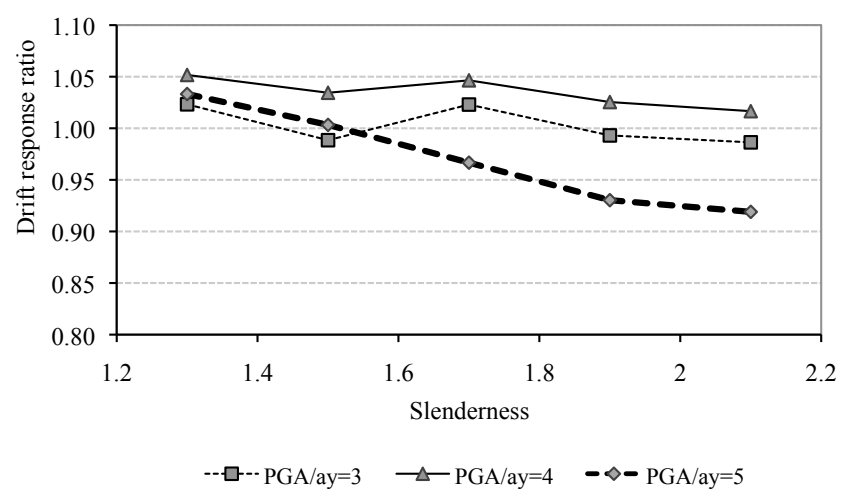

(a) Ratio of peak drift predictions (rigid-plastic to nonlinear model) when $15 \%$ of the total lateral strength is contributed by flexural plastic hinges for the Beverly Hills Station 1994 Northridge earthquake record.

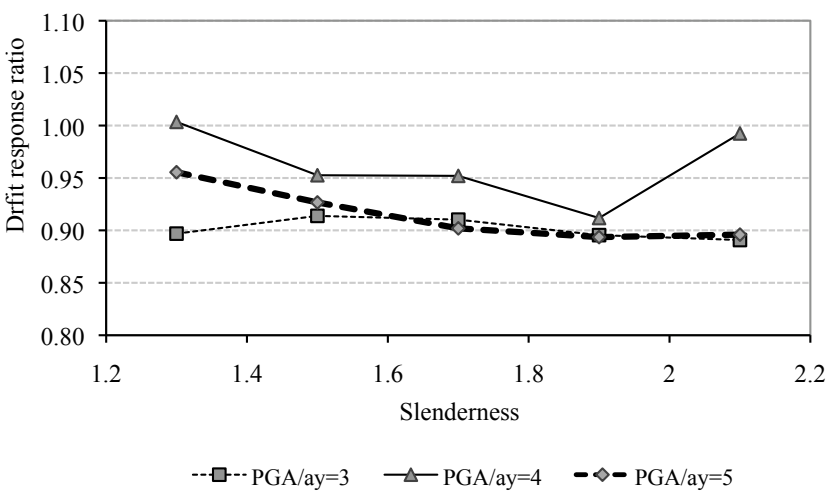

(b) Ratio of peak drift predictions (rigid-plastic to nonlinear model) when $30 \%$ of the total lateral strength is contributed by flexural plastic hinges for the Beverly Hills Station 1994 Northridge earthquake record.

Figure 10: Effect of brace slenderness and ratio $P G A / a_{y}$ in the accuracy of rigid-plastic predictions. 


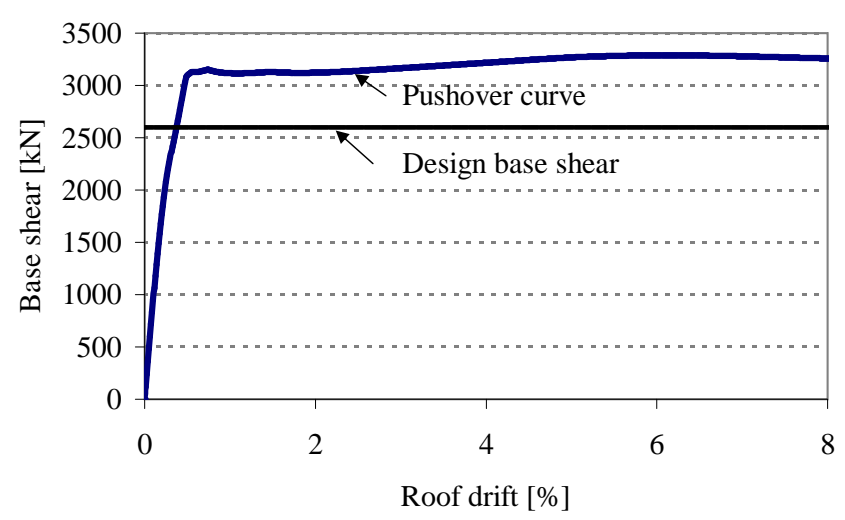

(a) Pushover curve for the four-storey dual structure.

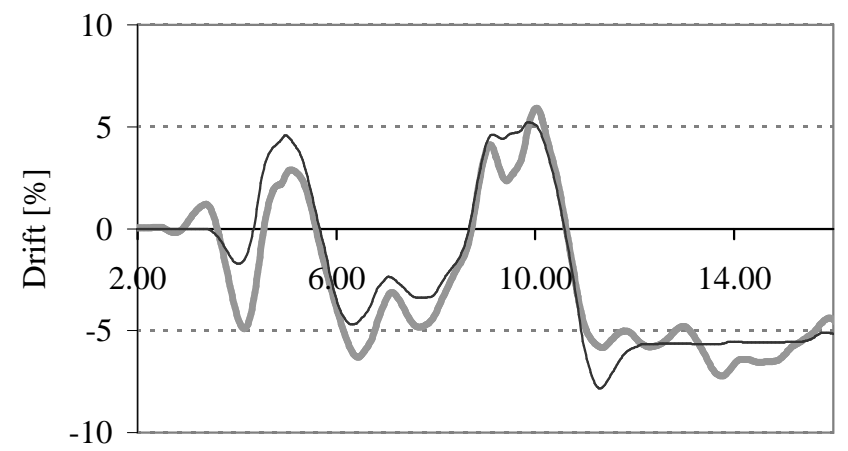

Time $[\mathrm{s}]$

- Refined non-linear —_Equivalent rigid-plastic

(c) Drift histories at effective height under scaled El Centro record with $P G A / a_{y}=3$.

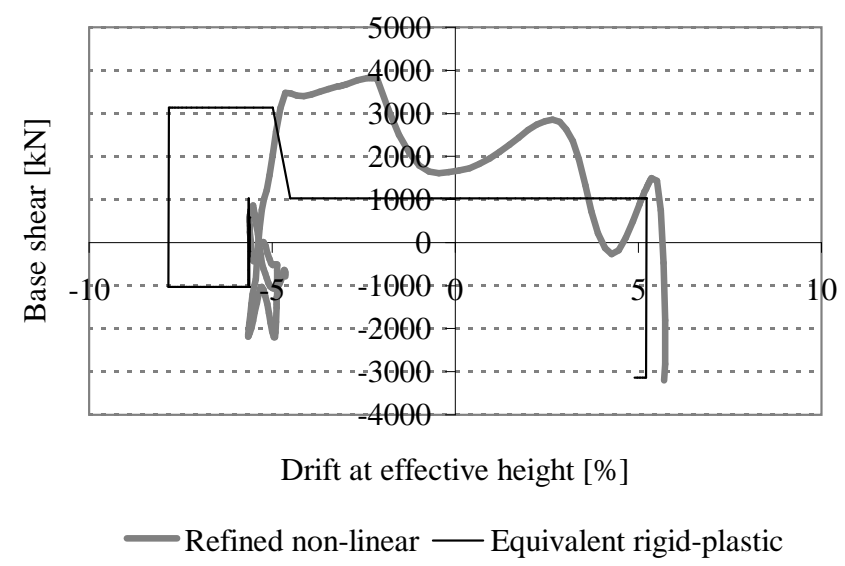

(b) Hysteretic behaviour of the dual four-storey building and the rigid-plastic model under scaled El Centro record with $P G A / a_{y}$ of 3 .

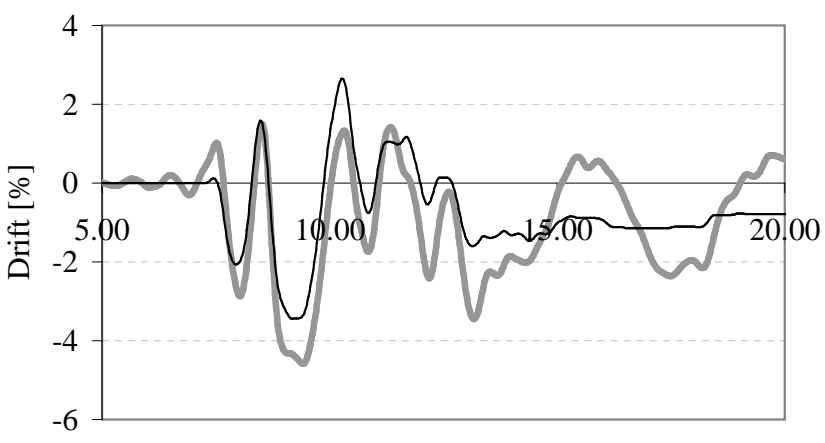

Time [s]

Refined non-linear — Equivalent rigid-plastic

(d) Drift histories at effective height under scaled JMA Kobe record with $P G A / a_{y}=3$.

Figure 11: Rigid-plastic analysis of a four-storey dual frame. 


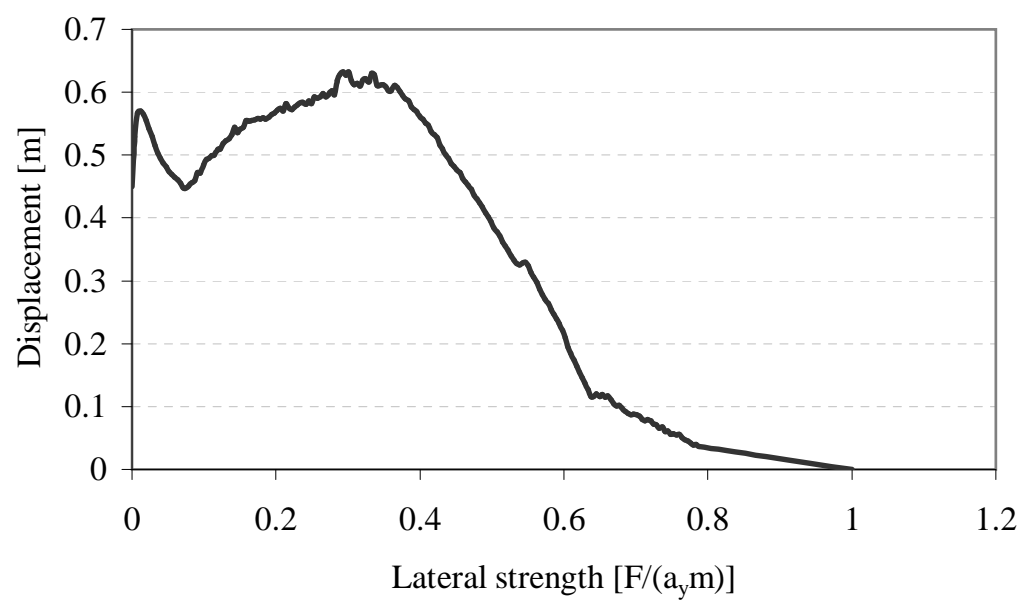

Figure 12: Rigid-plastic relationship between lateral strength and peak displacement for a dual system with flexural strength of $20 \%$ of the total capacity when subjected to the 1994 Northridge earthquake Sylmar Station record. 

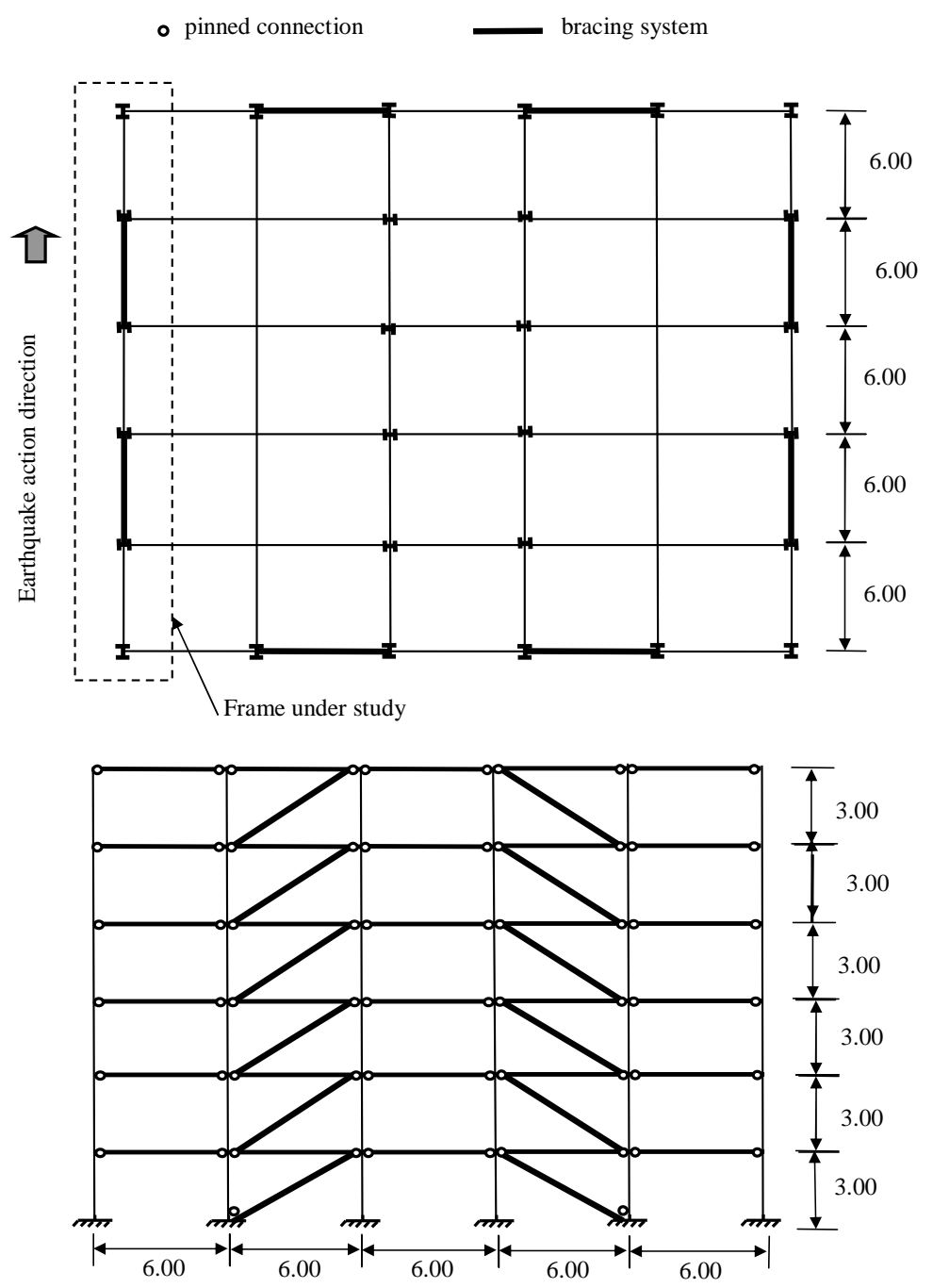

Figure 13: Plan layout and elevation of the six-storey steel frame with fixed bases used for design. 


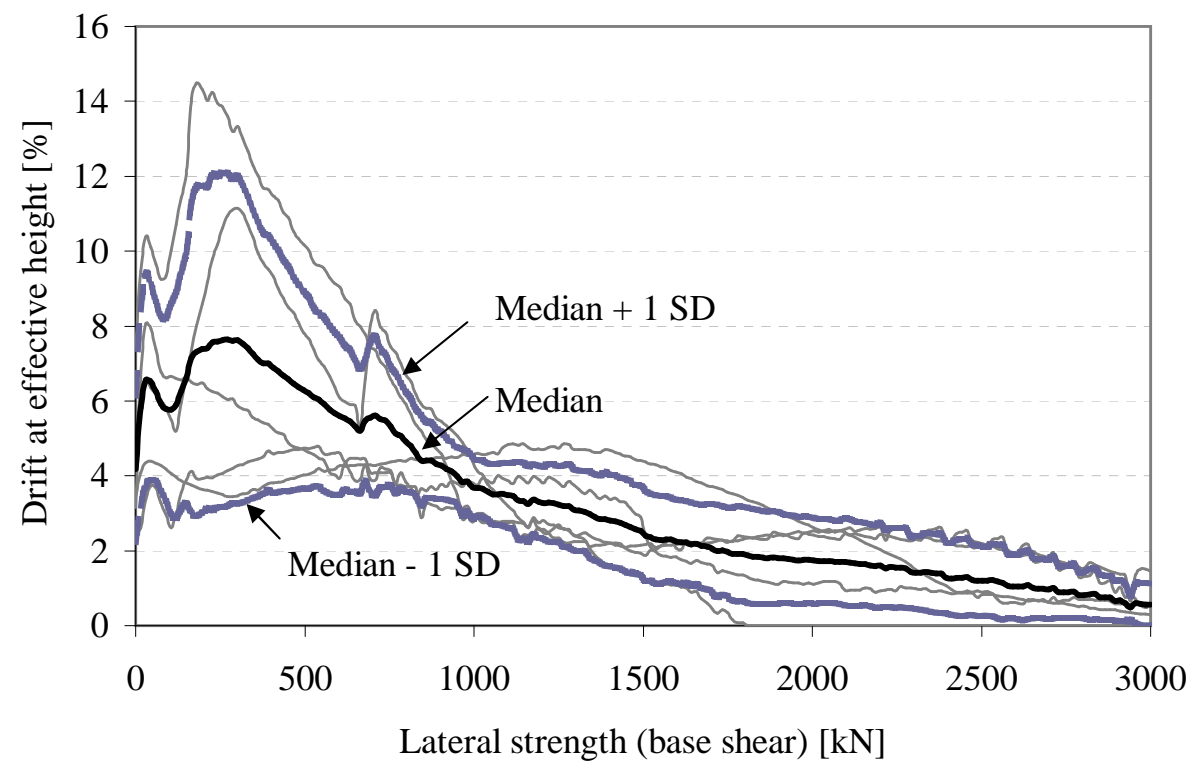

Figure 14: Drift at effective height vs. base shear relationship obtained by means of equivalent dual rigid-plastic oscillators with flexural resistance of $20 \%$ of the total lateral capacity of the building. Curves corresponding to each of the five records used are presented (thin lines) and the values corresponding to the median and median \pm 1 standard deviation are highlighted. The standard deviation corresponding to $3.5 \%$ design drift is $\pm 0.8 \%$. 


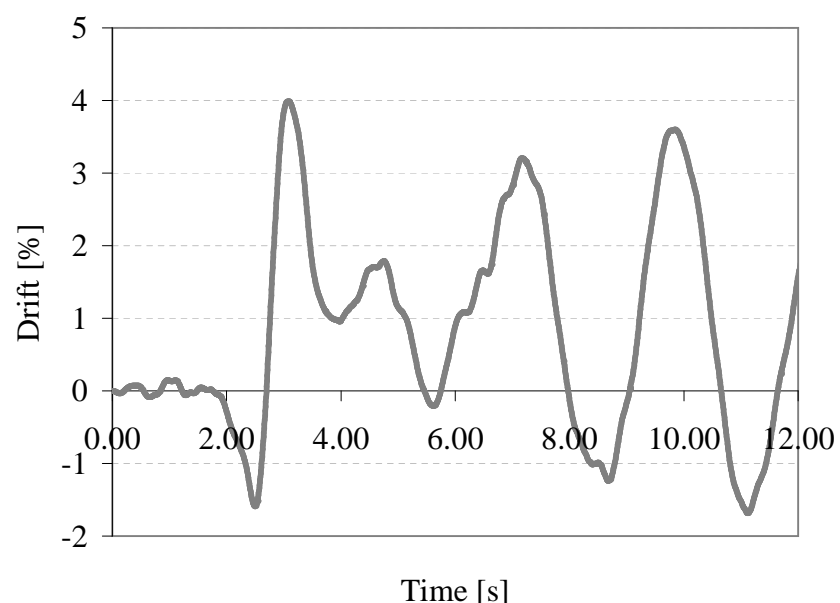

(a) 1994 Northridge earthquake record scaled by a factor of 1.29 .

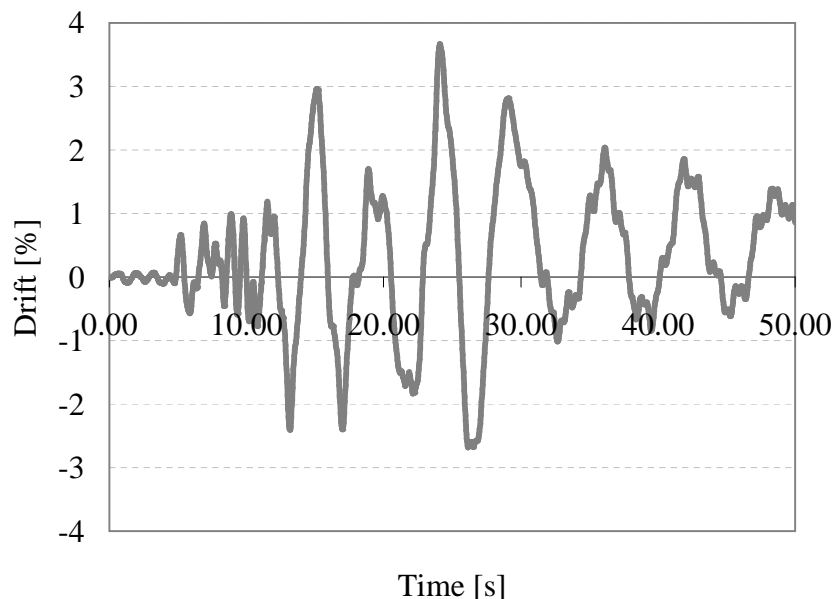

(b) 1974 Tabas earthquake record scaled by a factor of 1.08 .

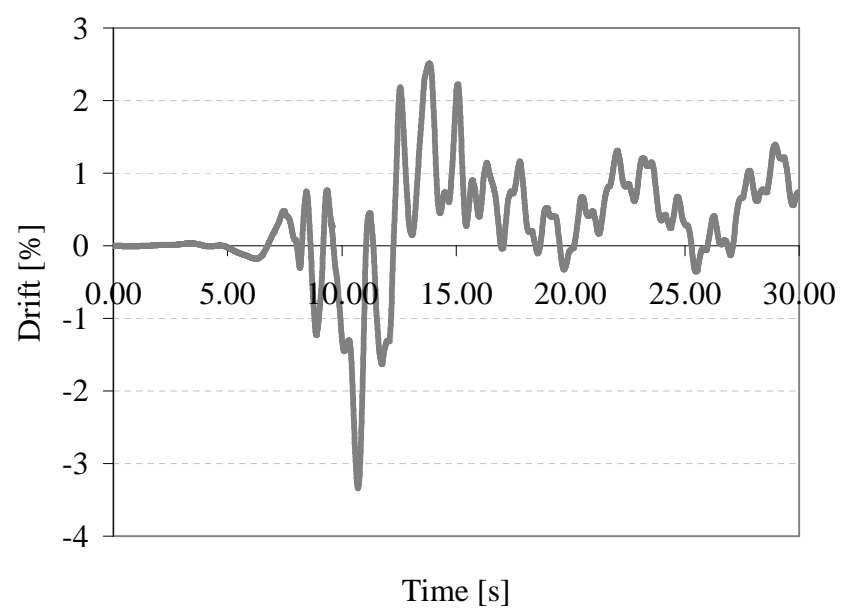

(c) Simulated Elysian Park record.

Figure 15: Drift at equivalent height of the 6-storey steel braced building with fixed columns when subjected to records corresponding to a $2 \%$ probability of exceedance in Los Angeles area. 


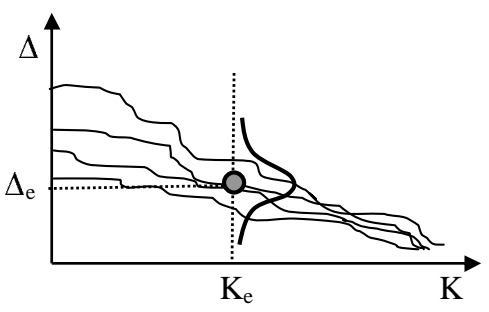

Displacement-stiffness relationships for damage prevention (serviceability) stage. From elastic response histories.

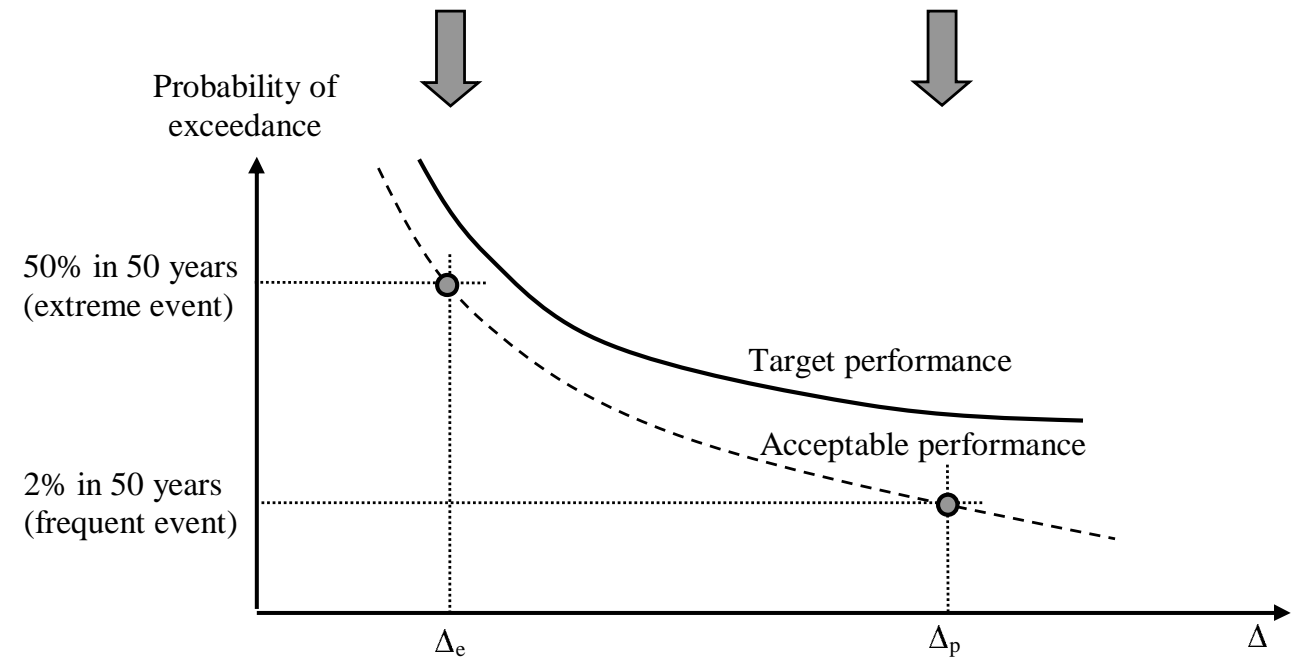

Figure 16: Seismic design framework with de-coupled assignment of stiffness and capacity based on elastic and rigid-plastic models. 